\title{
Pengaruh Pendidikan dan Pelatihan Terhadap \\ Prestasi Kerja Karyawan di PT.Telekomunikasi Indonesia (Telkom) Regional VII Gorontalo
}

\author{
Nadila Septiani Putri ${ }^{1}$ \\ Andi Yusniar Mendo ${ }^{2}$ \\ Agus Hakri Bokingo ${ }^{3}$ \\ Jurusan Manajemen, Fakultas Ekonomi, \\ Universitas Negeri Gorontalo \\ Agushakri@ung.ac.id
}

\begin{abstract}
This study aims to determine how much influence Education and Training on Employee Performance at PT. Indonesian Telecommunications (Telkom) Regional VII Gorontalo. The sample in this study were 67 people. Then the data analysis uses simple linear regression with the help of SPSS version 22. The results of the study show that the coefficient of determination $R 2$ is 0.406 . This value means that $40.6 \%$ of Work Achievement at PT. Telekomunikasi Indonesia (Telkom) Gorontalo Regional VII is influenced by the Education and Training program conducted by the company. The influence of other variables on employee performance is $59.4 \%$.

Keywords : Education and Training, employee work performance.

Abstrak

Penelitian ini bertujuan untuk mengetahui seberapa besar pengaruh Pendidikan dan Pelatihan terhadap Prestasi Kerja Karyawan pada PT. Telekomunikasi Indonesia (Telkom) Regional VII Gorontalo. Sampel dalam penelitian ini sebanyak 67 orang. Kemudian analisis data menggunakan regresi linear sederhana dengan bantuan program SPSS versi 22. Hasil Penelitian menunjukkan bahwa nilai koefisien determinasi $R^{2}$ sebesar 0,406 . Nilai ini berarti bahwa sebesar 40,6\% dari Prestasi Kerja pada PT. Telekomunikasi Indonesia (Telkom) Regional VII Gorontalo dipengaruhi oleh program Pendidikan dan Pelatihan yang dilakukan perusahaan. Adapun pengaruh dari variabel lain terhadap Kinerja karyawan sebesar 59,4\%.
\end{abstract}

Kata Kunci : Pendidikan dan Pelatihan, Prestasi kerja karyawan.

\section{PENDAHULUAN}

Pendidikan dan pelatihan merupakan kunci dalam manajemen yang memainkan peran penting dan strategis dalam meningkatkan prestasi kerja (Sutrisno, 2011:151). Pengembangan sumber daya manusia melalui pendidikan dan pelatihan merupakan fungsi operasional dalam manajemen sumber daya manusia. Salah satu wahana paling efektif yang dapat dan harus digunakan oleh perusahaan untuk mengembangkan karyawannya melalui pemberian pendidikan dan pelatihan. Pemberian pendidikan dan pelatihan ini bertujuan untuk meningkatkan 
kemampuan teknis, teoritis, konsepsual dan moral karyawan agar nantinya karyawan mampu mencapai hasil kerja yang optimal sehingga karyawan bersemangat untuk bekerja pada perusahaan. Pendidikan dan pelatihan karyawan dianggap semakin penting manfaatnya, karena sumber daya manusia adalah harta atau asset berharga yang dimiliki perusahaan dan juga yang menentukan keberhasilan perusahaan untuk mencapai tujuan. Selain itu maksud dilaksanakannya pendidikan dan pelatihan dalam perusahaan adalah karena adanya tuntutan pekerjaan atau jabatan sebagai akibat kemajuan ilmu dan teknologi serta semakin ketatnya persaingan diantara perusahaan yang sejenis.

Program pendidikan dan pelatihan karyawan di harapkan dapat memberikan motivasi bagi karyawan dalam meningkatkan keterampilan kinerja pegawai dan selanjutnya mampu meningkatkan prestasi kerja karyawan. Pendidikan dan pelatihan tersebut merupakan salah satu fungsi tradisional manajemen sumber daya manusia yang nantinya mampu meningkatkan prestasi kerja karyawan. Menurut Mangkunegara (2002:33) prestasi kerja adalah hasil kerja secara kualitas dan kuantitas yang dicapai oleh seorang pegawai dalam melaksanakan tugasnya sesuai dengan tanggung jawab yang diberikannya.

Banyak faktor yang mempengaruhi prestasi kerja, faktor-faktor yang mempengaruhi prestasi kerja antara lain adalah : kepemimpinan, lingkungan kerja, disiplin kerja, motivasi kerja, pendidikan dan pelatihan kerja (Sutrisno, 2011:151). Pernyataan diatas di perkuat oleh penelitian Moses (2012) mendapatkan hasil bahwa pendidikan dan pelatihan kerja berpengaruh terhadap prestasi kerja karyawan, maka dari itu dalam penelitian ini hanya membahas faktor pendidikan dan pelatihan yang mempengaruhi prestasi kerja karyawan.

PT Telkom Indonesia (Persero) Tbk (Telkom) adalah Badan Usaha Milik Negara (BUMN) yang bergerak di bidang jasa layanan teknologi informasi dan komunikasi (TIK) dan jaringan telekomunikasi di Indonesia. Pemegang saham mayoritas Telkom adalah Pemerintah Republik Indonesia sebesar $52.09 \%$, sedangkan $47.91 \%$ sisanya dikuasai oleh publik. Saham Telkom diperdagangkan di Bursa Efek Indonesia (BEI) dengan kode "TLKM" dan New York Stock Exchange (NYSE) dengan kode "TLK". Telkom juga menjadi pemegang saham mayoritas di 13 anak perusahaan, seperti PT.Telekomunikasi Seluler (Telkomsel), Telkom Akses, Telkom Metra. Telkom mengklaim sebagai perusahaan telekomunikasi terbesar di Indonesia, dengan jumlah pelanggan telepon tetap sebanyak 15 juta dan pelanggan telepon seluler sebanyak 104 juta.

Dalam upaya bertransformasi menjadi digital telecommunication company, TelkomGroup mengimplementasikan strategi bisnis dan operasional perusahaan yang berorientasi kepada pelanggan (customer-oriented). Transformasi tersebut akan membuat organisasi TelkomGroup menjadi lebih lean (ramping) dan agile (lincah) dalam beradaptasi dengan perubahan industri telekomunikasi yang berlangsung sangat cepat. Organisasi yang baru juga diharapkan dapat meningkatkan efisiensi dan efektivitas dalam menciptakan customer experience yang berkualitas.

Kegiatan usaha Telkom Group bertumbuh dan berubah seiring dengan perkembangan teknologi, informasi dan digitalisasi, namun masih dalam koridor industri telekomunikasi dan 
informasi. Hal ini terlihat dari lini bisnis yang terus berkembang melengkapi legacy yang sudah ada sebelumnya. Saat ini TelkomGroup mengelola 6 produk portofolio yang melayani empat segmen konsumen, yaitu korporat, perumahan, perorangan dan segmen konsumen lainnya. Indikasi turunnya prestasi kerja karyawan nampak dalam pencapaian kinerja perusahaan masih dibawah target yang telah ditentukan perusahaan. Penyebab turunnya prestasi kerja karyawan ini karena kemampuan karyawan kurang memahami cara penggunaan aplikasi komputer yang terbaru. Berikut ini metode penilaian yang digunakan dalam menilai prestasi kerja karyawan.

Tabel.1. Sasaran Kerja Individu (SKI) PT.Telekomunikasi Indonesia (Telkom) Regional VII Gorontalo

\begin{tabular}{|c|c|c|c|c|c|c|}
\hline No & SKU & $\begin{array}{l}\text { Bobot } \\
\text { SKU }\end{array}$ & Program & $\begin{array}{l}\text { Bobot } \\
\text { Program }\end{array}$ & $\begin{array}{l}\text { Target } \\
\text { Waktu }\end{array}$ & $\begin{array}{l}\text { Target } \\
\text { Output }\end{array}$ \\
\hline \multirow[t]{12}{*}{1} & FINANCIAL & $55 \%$ & & & & \\
\hline & & & FINANCIAL & $55 \%$ & & \\
\hline & & & Telkom Group Average Financial Ach & $5 \%$ & & \\
\hline & & & Incremental Revenue to Capex (IR2C) & $2 \%$ & & \\
\hline & & & TREG - NFinancial Mobile Achv & $2 \%$ & & \\
\hline & & & Witel - Financial ( revenue) EBIS Achv & $10 \%$ & & \\
\hline & & & $\begin{array}{l}\text { Witel - Financial Cons Indihome Revenue } \\
\text { Consumer }\end{array}$ & $15 \%$ & & \\
\hline & & & TREG - Financial ( revenue ) EBIS Achv & $2 \%$ & & \\
\hline & & & TREG - Financial ( revenue ) WIB & $2 \%$ & & \\
\hline & & & TREG - Financial ( revenue ) Consumer & $2 \%$ & & \\
\hline & & & Witel - Financial ( revenue) WIB & $10 \%$ & & \\
\hline & & & $\begin{array}{l}\text { Witel - Financial Cons Indihome EBITDA } \\
\text { Commerce }\end{array}$ & $5 \%$ & & \\
\hline \multirow[t]{10}{*}{2} & CUSTOMER & $30 \%$ & & & & \\
\hline & & & a. Customer Acquisition Achievement & $15 \%$ & & \\
\hline & & & $\begin{array}{l}\text { Consumer Acquisition Achievement - Witel } \\
\text { perspective. - Lis Indihome }\end{array}$ & $4 \%$ & & \\
\hline & & & Quality Of Sales Indihome ( 180 retention ) & $3 \%$ & & \\
\hline & & & Chun rate Indihome & $3 \%$ & & \\
\hline & & & EBIS Average Acquisition Ach & $5 \%$ & & \\
\hline & & & b. CUSTOMER EXPERIENCE ACH & $15 \%$ & & \\
\hline & & & SLG Fulfillment \& Assurance EGBIS & $5 \%$ & & \\
\hline & & & SLG Fulfillment \& Assurance WIB & $5 \%$ & & \\
\hline & & & SLG Fulfillment \& assurance Consumer & $5 \%$ & & \\
\hline \multirow[t]{5}{*}{3} & $\begin{array}{l}\text { INTERNAL } \\
\text { BUSINESS } \\
\text { PROCESS }\end{array}$ & $10 \%$ & & & & \\
\hline & & & LEAN & $10 \%$ & & \\
\hline & & & Collection Ratio Achievement & $6 \%$ & & \\
\hline & & & Network Performance & $2 \%$ & & \\
\hline & & & Compliance SOA & $2 \%$ & & \\
\hline \multirow[t]{3}{*}{4} & $\begin{array}{l}\text { LEARNING \& } \\
\text { GROWTH }\end{array}$ & $5 \%$ & & & & \\
\hline & & & LEAN & $10 \%$ & & \\
\hline & & & Culture Program & $5 \%$ & & \\
\hline \multicolumn{2}{|c|}{ Jumlah } & $100 \%$ & & $100 \%$ & & \\
\hline
\end{tabular}

Sumber Data: PT.Telekomunikasi Indonesia (Telkom) Regional VII Gorontalo 2019 
Maka dari itu PT.Telekomunikasi Indonesia (Telkom) Regional VII Gorontalo, khususnya pada bagian Human Resources (HR) and finance mengadakan pendidikan dan pelatihan kerja karyawan yang bertujuan untuk meningkatkan pencapaian target tiap tahun dan meningkatkan prestasi kerja karyawan. Saat ini karyawan yang diangkat dari pendidikan umum yang berstatus outsourcing sehingga masih diperlukan pelatihan.

Dalam menilai karyawan PT.Telekomunikasi Indonesia (Telkom) Regional VII Gorontalo menggunakan metode SKI (Sasaran Kerja Individu). Sasaran Kerja Individu biasanya digunakan untuk mengukur kinerja karyawan pada perusahaan secara keseluruhan sehingga operation head atau EVP dapat menentukan langkah apa yang sebaiknya diambil. Penilai menggunakan sistem sasaran kerja individu dilakukan sendiri oleh operation head.

Dari hasil obsrevasi awal dan wawancara pada PT.Telekomunikasi Indonesia (Telkom) Regional VII Gorontalo masih terdapat karyawan yang kurang memahami kerja dibeberapa bidang seperti payment karena masih terdapat karyawan yang kurang memahami kerja dibidang payment yang bertugas untuk mengatasi apabila adanya pelanggan yang menunggak pembayaran karena kebanyakkan karyawan belum memahami aplikasi. Berdasarkan latar belakang yang ada maka peneliti perlu mengangkat judul "Pengaruh Pendidikan dan Pelatihan Terhadap Prestasi Kerja Karyawan Di PT.Telekomunikasi Indonesia (Telkom) Regional VII Gorontalo".

\section{METODE}

Penelitian ini menggunakan metode kuantitatif. Populasi dalam penelitian ini adalah seluruh karyawan di PT.Telekomunikasi Indonesia (Telkom) Regional VII Gorontalo berjumlah sebanyak 202 karyawan

\section{HASIL DAN PEMBAHASAN}

Tabel 2. Analisis regresi penelitian

\begin{tabular}{|l|c|c|c|c|c|}
\hline \multicolumn{7}{|c|}{ Coefficients $^{\mathrm{a}}$} \\
\hline \multirow{2}{*}{ Model } & \multicolumn{2}{|c|}{$\begin{array}{c}\text { Unstandardized } \\
\text { Coefficients }\end{array}$} & $\begin{array}{c}\text { Standardized } \\
\text { Coefficients }\end{array}$ & & \\
\cline { 2 - 7 } 1 & B & Std. Error & Beta & $\mathrm{t}$ & Sig. \\
\cline { 2 - 7 } & $\mathbf{1 4 . 3 2 5}$ & 7.073 & & 2.025 & 0.047 \\
\hline $\begin{array}{l}\text { Pendidikan dan } \\
\text { Pelatihan }\end{array}$ & $\mathbf{0 . 7 3 3}$ & 0.110 & 0.637 & 6.665 & 0.000 \\
\hline \multicolumn{2}{|l|}{ a. Dependent Variable: Prestasi kerja } & & & & \\
\hline
\end{tabular}

Sumber: data primer diolah, 2019 
Berdasarkan analisis regresi pada tampilan output SPSS tabel 4.11, maka diketahui persamaan regresinya: $\hat{\gamma}=\mathbf{1 4 , 3 5 2}+\mathbf{0 , 7 3 3}$ Dari persamaan regresi yang diperoleh, dapat dijelaskan bahwa:

1. Nilai konstan sebesar 14,352 untuk variabel Prestasi kerja karyawan PT. Telkom Regional VII Gorontalo (Y), yang menjelaskan bahwa jika seluruh model dalam penelitian ini atau variabel Pendidikan dan Pelatihan (X) karyawan tidak memiliki pengaruh, maka nilai Prestasi kerjanya sebesar nilai konstan yang ada.

2. Nilai regresi untuk variabel Pendidikan dan Pelatihan (X) karyawan PT. Telkom Regional VII Gorontalo adalah sebesar 0,733, yang menjelaskan bahwa jika variabel Pendidikan dan Pelatihan mengalami kenaikan 1 point/satuan seperti: Pendidikan dan Pelatihan menigkatkan kinerja dan insiatif kerja karyawan, maka akan meningkatkan atau menambah nilai dari Prestasi kerja sebesar 0,733 poin.

Tabel 3. Uji t

\begin{tabular}{|c|c|c|c|c|c|c|}
\hline \multicolumn{7}{|c|}{ Coefficients $^{\mathrm{a}}$} \\
\hline \multirow{2}{*}{\multicolumn{2}{|c|}{ Model }} & \multicolumn{2}{|c|}{$\begin{array}{l}\text { Unstandardized } \\
\text { Coefficients }\end{array}$} & \multirow{2}{*}{$\begin{array}{c}\text { Standardized } \\
\text { Coefficients }\end{array}$} & \multirow[b]{2}{*}{$t$} & \multirow[b]{2}{*}{ Sig. } \\
\hline & & B & Std. Error & & & \\
\hline \multirow[t]{2}{*}{1} & (Constant) & 14.325 & 7.073 & & 2.025 & 0.047 \\
\hline & Pendidikan dan Pelatihan & 0.733 & 0.110 & 0.637 & 6.665 & 0.000 \\
\hline & pendent Variable: Presta & & & & & \\
\hline
\end{tabular}

Sumber: data primer diolah, 2019

Berdasarkan tampilan tabel di atas dapat dijelaskan bahwa nilai t-hitung untuk variabel Pendidikan dan Pelatihan karyawan PT. Telkom Regional VII Gorontalo adalah sebesar 6,665 dengan nilai signifikansi sebesar 0,000. Pada penjelasan sebelumnya bahwa telah diketahui nilai $t$ tabel sebesar 1,669 yang apabila nilai keduanya dibandingkan maka nilai $t$ hitung lebih besar dari nilai $t$ tabel. Adapun berdasarkan nilai signifikansinya $(0,000)$ masih jauh lebih kecil dari nilai probabilitas alpha $(0,05)$. Berdasarkan temuan tersebut, maka dapat disimpulkan bahwa hipotesis yang disusun sebelumnya terbukti atau diterima ( $H O$ ditolak dan Ha diterima), yang menjelaskan secara spesifik bahwa Pendidikan dan Pelatihan yang diterima karyawan memiliki pengaruh yang signifikan terhadap Kinerjanya. 


\section{SIMPULAN}

Setiap indikator yang berisi pernyataan-pernyataan yang mewakili variabel penelitian yakni Pendidikan dan Pe;atihan, serta variable Prestasi Kerja di PT. Telkom Gorontalo memiliki keandalan instrumen yang baik, dan jawaban yang konsisten dari responden. Hasil uji regresi menunjukkan bahwa variabel Pendidikan dan Peatihan (X) memiliki pengaruh yang signifikan terhadap Prestasi kerja $(\mathrm{Y})$ dengan melihat hasil koefisien regresi dimana t hitung lebih besar dari t tabel, sehingga hipotesis yang disusun telah terbukti dan diterima. Variabel Pendidikan dan Pelatihan memiliki pengaruh sebesar 40,6\% terhadap Prestasi kerja karyawan PT. Telkom Gorontalo, selebihnya sebesar 59,4\% dipengaruhi oleh variabel lain yang tidak diteliti. Penelitian ini membuktikan bahwa semakin sering dan tepat pelaksanaan Pendidikan dan Pelatihan seperti maka akan semakin memotivasi karyawan dala bekerja, yang akan mempengaruhi prestasi kerjanya.

IV. SARAN

Pendidikan dan Pelatihan serta Prestasi Kerja sebagai salah satu faktor penentu keberhasilan perusahaan. Sistem manajemen PT. Telkom Gorontalo dapat memperhatikan peningkatan Prestasi kerjanya melalui pelaksanaan Pendidikan dan Pelatihan, sehingga karyawan dapat termotivasi dalam bekerja, dan memiliki kualitas kerja dan berdampak pada prestasi kerjanya. Penelitian ini dapat berguna sebagai bahan informasi, baik bagi akademisi, dan pihak lainnya, yang membahaspraktek manajemen Sumberdaya manusia khususnya menyangkut Pendidikan dan Pelatihan dan Prestasi kerja. 


\section{DAFTAR PUSTAKA}

AA. Anwar Prabu Mangkunegara, (2009). Manajemen Sumber Daya Manusia Perusahaan. Bandung: Rosda.

Achmad S. Ruky, (2001). Sistem Manajemen Kinerja. PT. Gramedia, Jakarta.

Cherrington, David J, 1995. The Management of Human Resources (4th Edition).New Jersey: Prentice Hall Inc.

Dessler, Gary. (2015). Manajemen Sumber Daya Manusia. Jakarta: Salemba Empat.

Handoko, T. Hani. (2001). Manajemen Personalia dan Sumber Daya Manusia. Yogyakarta : BPFE. (2010). Manajemen Personalia \& Sumber daya Manusia. BPFE-Yogyakarta.

Nasution, Mulia. 2000. Manajemen Personalia. Jakarta: Djambatan.

Priansa, Donni. 2017. Manajemen Pelayanan Prima.Bandung.Alfabeta.

Rivai, Veithzal. (2004). Manajemen Sumber Daya Manusia untuk Perusahaan dari Teori ke Praktik. PT Rajagrafindo Persada, Jakarta.

Sadili, Samsudin. 2006. Manajemen Sumber Daya Manusia. Bandung : Pustaka Setia. 